\title{
PROGRAMA MUNICIPAL DE AQUISIÇÃO DE ALIMENTOS COMO POLÍTICA PÚBLICA PARA CONSOLIDAR A AGRICULTURA FAMILIAR EM MARACANAÚ-CE
}

\author{
NUNES, Elizângela Assunção ${ }^{1}$ \\ SILVA JÚNIOR, José Maria Tupinambá da ${ }^{2}$ \\ GOMES, Hordênia Chagas Azevedo ${ }^{3}$ \\ GALERA JÚNIOR, José Roberto ${ }^{4}$
}

\begin{abstract}
RESUMO: O Programa de Aquisição de Alimentos (PAA) é um dos principais programas de compras institucionais do Brasil e representa um incentivo a construção de práticas favoráveis à comercialização para os agricultores familiares, além de garantir o acesso a alimentos em regularidade necessária para às populações em situação de insegurança alimentar e nutricional. Em Maracanaú-CE, já é executado o PAA com verbas federais, entretanto, visando garantir a continuidade da aquisição de alimentos dos agricultores familiares residentes no município, após a finalização dos recursos disponibilizados anualmente ao PAA Federal, a Prefeitura aprovou uma Lei instituindo o PAA Municipal. Foram beneficiados com a execução do Programa, 52 agricultores da Reserva Indígena e 15 do Mucunã. Os produtos agropecuários mais fornecidos pelos produtores durante o período de execução do PAA foram frutas, hortaliças e carne suína. Concluiu-se que o PAA Municipal desempenha um papel significativo na melhoria do acesso à comercialização de produtos agropecuários pelos agricultores familiares de Maracanaú-CE, além de proporcionar acesso à alimentação adequada e saudável às pessoas atendidas na rede socioassistencial.
\end{abstract}

Palavras-chaves: Desenvolvimento local. Produtos agropecuários. Comercialização.

\section{MUNICIPAL FOOD PURCHASE PROGRAM AS PUBLIC POLICY FOR CONSOLIDATE OF FAMILY FARMING IN MARACANAÚ-CE}

\begin{abstract}
SUMMARY: The Food Purchase Program (PAA) is one of the main institutional purchasing programs in Brazil and represents an incentive for the construction of marketing practices for family farmers, as well as guaranteeing access to food in a regularity necessary for the populations in situation food insecurity. In Maracanaú-CE, the PAA is already executed with federal funds, however, in order to guarantee the continuity of the food acquisition of family farmers residing in the municipality, after finalization of the resources made available annually to the PAA Federal, the City Council approved a Law establishing the PAA Municipal. The program's beneficiaries benefited from 52 farmers from the Indigenous Reserve and 15 farmers from Mucunã. The most agricultural products provided by producers during the period of implementation of the PAA were fruits, vegetables and pork. It was concluded that the PAA Municipal plays a significant role in improving access to marketing of agricultural products by family farmers in Maracanaú-CE, as well as providing access to adequate and healthy food for people assisted in the socio-welfare network.
\end{abstract}

Keywords: Family farming. Agricultural products. Commercialization.

\footnotetext{
${ }^{1}$ Assistente Social da Prefeitura Municipal de Maracanaú-CE, Mestre em Planejamento e Políticas Públicas. E-mail: elizangelaassuncaonunes@gmail.com

2 Engenheiro Agrônomo da Prefeitura Municipal de Maracanaú-CE. Doutor em Ciência do Solo E-mail: jmtsilvajunior@gmail.com;

Engenheira de Alimentos da Prefeitura Municipal de Maracanaú-CE. Mestre em Ciência e Tecnologia de Alimentos. E-mail: hordeniaazevedo@yahoo.com.br;

${ }^{4}$ Agente Administrativo da Prefeitura Municipal de Maracanaú-CE. E-mail: robertogalerajr@yahoo.com.br
} 


\section{INTRODUÇÃO}

A agricultura familiar tem se destacado no cenário nacional como importante setor na garantia da segurança alimentar e nutricional dos brasileiros pois é responsável por $70 \%$ da produção de alimentos que vão à mesa e são consumidos, diariamente, pela população. Diante desta realidade incontestável, políticas públicas de fomento têm sido direcionadas a esta parcela da sociedade, no intuito de maximizar o potencial de produção desses agricultores e possibilitar a permanência de grande parte das famílias no campo, bem como a continuidade da produção de alimentos, que abastecem os mercados locais e regionais (SILVA; FERREIRA, 2016).

Dentre as políticas públicas de fortalecimento da agricultura familiar, insere-se as compras públicas governamentais e que segundo Santana et al. (2017), o mercado institucional contribui para fortalecer os canais de comercialização locais e regionais, além de valorizar a biodiversidade, a produção orgânica e agroecológica e incentivar a formação de hábitos de alimentação saudáveis. Entre os Programas criados pelo Governo Federal com esse objetivo, destaca-se o Programa de Aquisição de Alimentos (PAA) que foi instituído pela Lei $\mathrm{n}^{\circ}$ 10.696/2003 e que conforme Baccarin et al. (2017) com a instituição do Programa, assumia-se a intenção de garantir a compra, a preços mais remuneradores do que os tradicionais, de produtos alimentícios dos agricultores familiares, ao mesmo tempo que se propunha a destiná-los para consumo de pessoas em situação de insegurança alimentar e nutricional.

No Brasil, após as eleições presidenciais de 2002 e da posse do presidente Luiz Inácio Lula da Silva, abriram-se espaços para a institucionalização de muitas ideias e reivindicações relacionadas ao tema da Segurança Alimentar e Nutricional (SAN) (GRISA; SCHNEIDER, 2014). Segundo Macedo et al. (2017), muitas das ações que buscam promover a SAN passam pelo fortalecimento de sistemas agroalimentares, assim, a SAN passa a ser considerada na formulação de diferentes políticas públicas, sempre atrelada a percepção da importância de se valorizar a agricultura familiar na construção de sistemas agroalimentares mais equitativos e localizados.

Atualmente, a temática de SAN é objeto de inúmeras discussões e pesquisas, em que o PAA tem emergido por meio de um projeto maior, construído por entes governamentais e não governamentais. $\mathrm{O}$ aspecto primordial do programa é minimizar os índices alarmantes de fome e miséria no país, porém é possível afirmar que este favoreceu o estabelecimento de outra política, a agrícola, uma vez que possibilitou a inserção dos agricultores familiares no mercado de comercialização de seus produtos (SILVA; FERREIRA, 2016). Conforme Triches e Grisa (2015) a abertura de mercados institucionais para os agricultores familiares, com o PAA e o Programa Nacional de Alimentação Escolar (PNAE), passa-se a rever o papel das compras governamentais no sentido de torná-las instrumentos estatais de incentivo e de criação de mercados para a agricultura familiar e, ao mesmo tempo, promotoras de segurança alimentar e viabilizadoras de melhorias na qualidade da alimentação da população beneficiada pelos Programas.

No município de Maracanaú-CE, o PAA, na modalidade Compra Com Doação Simultânea, é executado pela Prefeitura desde o ano 2007 com recursos da União, sendo que, em 2012 foi assinado o Termo de Adesão entre o Ministério do Desenvolvimento Social (MDS) e o Governo Municipal com validade de 5 anos. Entretanto, a ocorrência de interrupções na execução do Programa devido aos trâmites legais de prestação de contas e publicação de Portaria no Diário Oficial da União com dados referentes ao próximo Plano Operacional a ser executado, fizeram com que os agricultores familiares do município demandassem por uma alternativa de continuidade à comercialização dos seus produtos agrícolas.

Em decorrência disso e como uma forma de incentivar a agricultura familiar em Maracanaú, a Prefeitura aprovou a Lei Municipal $n^{\circ} 2.052$, de 13 de agosto de 2013, instituindo no âmbito do município de Maracanaú, o Programa de Aquisição de Alimentos (PAA Municipal), para a aquisição de gêneros 
alimentícios de agricultores familiares residentes no município. Considerando o contexto relatado, o objetivo do trabalho foi analisar a operacionalização do PAA Municipal como instrumento para fomentar a agricultura familiar em Maracanaú-CE e beneficiar com o acesso a alimentos de qualidade a população atendida pela Rede de SAN e Entidades Socioassistenciais existente no município.

\section{FUNDAMENTAÇÃO TEÓRICA}

\subsection{A Agricultura Familiar no Brasil}

O universo agrário brasileiro é um espaço extremamente complexo, seja em função da grande diversidade da paisagem (meio físico, ambiente, variáveis econômicas, entres outros fatores), seja em virtude da existência de diferentes tipos de atores sociais (camponês, posseiro, agricultor familiar, dentre outros), os quais têm interesses particulares e estratégias próprias de sobrevivência e de produção. É nesse cenário que se apresentam as questões referentes à agricultura familiar no Brasil (LUNAS; CARDOSO JÚNIOR; LIMA, 2017).

De acordo com Biancardi et al. (2017) a expressão "agricultura familiar", para se referir a uma categoria socioeconômica diferenciada no meio rural, se tornou mais usual nas ciências agrárias a partir dos anos 1990. Antes desse período, segundo Bezerra e Schlindwein (2017) agricultura familiar recebeu várias definições, sendo caracterizada como agricultura de subsistência, de pequena produção e pobreza rural. No contexto agropecuário, insere-se a agricultura patronal e a agricultura familiar, sendo ambos segmentos produtivos de grande relevância para o país (NASCIMENTO et al., 2016). Azevedo e Pessôa (2011) relatam algumas características da agricultura não familiar, ou seja, da agricultura patronal, como: organização centralizada, ênfase na especialização e práticas agrícolas patronáveis, separação dos fatores de gestão e de trabalho, predominância do trabalho assalariado, tecnologias direcionadas que buscam a redução da mão de obra e foco em insumos comprados.

O termo "agricultura familiar" teve avanços significativos nas últimas décadas com relação à sua definição e compreensão de suas características (SCHNEIDER; CASSOL, 2014). De acordo com Conti, Bazotti e Radomsky (2015), a categoria "agricultor familiar" passou a ocupar centralidade nos debates teóricos e diversos estudos trazem explicações sobre a permanência das famílias no espaço rural, renovando o debate e permitindo explanações sobre as definições em torno da agricultura familiar - mais recentemente "agriculturas familiares", expressão que no país parece conceder primazia à diversidade social rural.

Junto com essa definição de ordem conceitual houve, sobretudo, nas duas últimas décadas um expressivo avanço nas definições de ordem normativa e operacional da agricultura familiar. Foram publicadas leis que visavam definir e regulamentar organizações e atividades de produção e comercialização da agricultura familiar. Entre elas, é importante destacar a Lei Federal no 11.326 , de 24 de julho de 2006, que define como empreendedor familiar e agricultor familiar, no artigo $3^{\circ}$, aquele que realiza atividades no meio rural, atendendo, simultaneamente, as seguintes características primordiais: não possuir área maior do que 4 (quatro) módulos fiscais; a mão de obra utilizada nas atividades econômicas ser predominantemente familiar; maior percentual da renda ser obtida das atividades econômicas do estabelecimento e dirija seu estabelecimento ou empreendimento com sua família. Desta forma, para Hanashiro et al. (2011) é possível perceber que, a produção da agricultura familiar abastece predominantemente o mercado interno, enquanto o principal objetivo econômico da agricultura patronal é o mercado externo. 
Conforme Paula, Kamimura e Silva (2014) com o estabelecimento dessas políticas de apoio à agricultura familiar e à publicação dessas leis, vem à tona uma questão até então renegada, que é a importância da agricultura familiar no Brasil. No Brasil, os programas de políticas públicas foram voltados para os grandes agricultores e somente nas últimas décadas é que o Governo viabilizou ações para a agricultura familiar. Souza-Esquerdo e Bergamasco (2015) ratificam essa ideia, uma vez que, para esses autores, no Brasil, a grande propriedade foi o modelo socialmente reconhecido, sendo as políticas públicas direcionadas a essa categoria. No período recente houve, por parte do Estado, uma tentativa de fortalecimento da agricultura familiar no que diz respeito a estímulos através de linhas de crédito rural e ampliação dos canais de comercialização, havendo o reconhecimento de sua importância.

Portanto, observa-se a necessidade de o Estado introduzir políticas públicas direcionadas para agricultura familiar, embasada em informações e análises confiáveis, pautada em princípios e valores socialmente aceitos e que trouxesse efeitos desejados para a melhoria da agricultura. Conforme Marques, Moal e Andrade (2014), as políticas públicas agroalimentares são definidas em razão das representações dos problemas agrícolas, alimentares e rurais, o que leva a uma determinada compreensão de que devam ser os objetivos da ação pública e de seus instrumentos. Segundo Secchi (2016) política pública é um conceito abstrato que se materializa com instrumentos concretos como, por exemplo, leis, programas, campanhas, obras, prestação de serviços, subsídios, impostos e taxas, decisões judiciais e muitos outros. Uma política pública é uma diretriz elaborada para enfrentar um problema público.

De acordo com Gazolla e Schneider (2013), o surgimento do Programa Nacional de Fortalecimento da Agricultura Familiar (PRONAF) em 1996, modificou a situação dos agricultores brasileiros. Pois o PRONAF pode ser considerado um marco na intervenção do Estado na agricultura brasileira, por que representa a incorporação efetiva dos agricultores familiares às políticas para o meio rural. O PRONAF foi instituído por meio do Decreto Presidencial nº 1.946 de 28 de junho de 1996, sendo concebido como uma política pública de valorização da agricultura familiar e de desenvolvimento do meio rural, e nestes termos, constituiu-se como alternativa econômica frente às desigualdades ao afrontar a agricultura familiar e a patronal nas políticas tradicionais de crédito (SILVA et al. 2015b).

Segundo Grisa, Wesz Junior e Buchweitz (2014), tratava-se, de um programa que articulava diversos instrumentos, como o crédito rural, a capacitação e profissionalização dos agricultores familiares e demais atores relacionados com a categoria, entre outras ações. Ainda que, após várias mudanças e reformulações, o PRONAF apresente-se basicamente como uma política de crédito rural - minimizando os outros instrumentos que também contribuiriam para promover o desenvolvimento rural, todavia, é provavelmente, a política agrícola de maior envergadura em termos de recursos financeiros disponibilizados e número de agricultores familiares beneficiados.

Após o lançamento do Pronaf em 1996, percebeu-se a necessidade de criar e articular outras políticas e programas visando integrar as ações governamentais para o segmento da agricultura familiar. A integração de políticas públicas voltadas para o desenvolvimento rural pode interferir nos aspectos socioeconômicos dos agricultores familiares. Relacionam-se fatores culturais, de renda, comercialização, diversificação da produção, aumento da área produtiva, etc., e estudá-las permite analisar a relação da dinâmica do ambiente com as políticas de intervenção estatal (SCHEUER et al., 2016).

Em 2003, ocorre a apresentação da principal política pública direcionada a área da Segurança Alimentar e Nutricional dos últimos anos, o Programa Fome Zero. De acordo com Salgado e Dias (2013) o Programa de Aquisição de Alimentos (PAA) surge como uma das principais ações estruturantes do Fome Zero, uma vez que, havia sido diagnosticado que as causas das situações de pobreza rural estavam relacionadas a dificuldade da pequena escala de produção, principalmente relativo à distribuição e à comercialização dos produtos. No PAA, são utilizados mecanismos de comercialização para a aquisição 
direta de alimentos produzidos por agricultores familiares, assentados da reforma agrária, comunidades indígenas e demais comunidades tradicionais, os quais são selecionados, geralmente, através de Chamada Pública (BIANCARDI et al., 2017).

\subsection{O Programa de Aquisição de Alimentos (PAA)}

Segundo Santana et al. (2017), a produção agrícola está fortemente caracterizada por riscos climáticos, incerteza quanto à incidência de pragas e doenças e riscos de mercado pela elevada instabilidade nos preços. Entretanto, para tentar atenuar esses problemas, o governo federal criou o mercado institucional para apoiar a produção por meio do aporte de crédito no âmbito do PRONAF e a comercialização e inserção no mercado mediante as compras pelo Programa de Aquisição de Alimentos (PAA) e o Programa Nacional de Alimentação Escolar (PNAE). Com isso, cria-se mercado para o excedente da produção gerada no âmbito da agricultura familiar individual e de suas organizações (associações, sindicatos e cooperativas).

De acordo com Rigon e Bezerra (2014), o PAA desburocratizou o processo de aquisição dos produtos da agricultura familiar, possibilitando ao Estado uma presença mais efetiva no apoio aos agricultores familiares e às famílias em situação de insegurança alimentar. Considera-se que a experiência do PAA constituiu um processo pedagógico, tanto para a gestão pública, que passou a realizar as compras institucionais mediante processos diferenciados de aquisição, como para determinados segmentos da agricultura familiar, que passaram a comercializar seu excedente de produção. O Decreto $\mathrm{N}^{\circ} 7.272$ foi publicado em 25 de agosto de 2010 e a partir dele, estabeleceu-se a Política Nacional de Segurança Alimentar e Nutricional (PNSAN), que oportunizaram o surgimento de importantes inovações no campo das políticas públicas, traduzidas na maior articulação entre os programas/ações de fortalecimento da agricultura familiar e os objetivos estratégicos de combate à fome e à desnutrição, estabelecidos pelo Governo Federal a partir de 2003.

O PAA foi instituído através do Art. 19 da Lei $\mathrm{N}^{\circ}$ 10.696, de 02 de julho de 2003, tendo a participação de movimentos sociais e da sociedade civil. Assim, o PAA entra em funcionamento com a perspectiva de garantir a disponibilidade de alimentos para a população em situação de insegurança alimentar, ao mesmo tempo em que objetiva promover a geração de renda para famílias de agricultores familiares em situação de vulnerabilidade social e econômica. Pode-se constatar que o Programa atua com os seguintes objetivos: comprar o alimento diretamente do pequeno agricultor, valorizando e estimulando a atividade da agricultura familiar, portanto fortalecendo esse segmento; e incentivar a organização dos trabalhadores em cooperativas e outras formas de arranjos produtivos; além disso, pode auxiliar, de maneira robusta, o combate à fome e à desnutrição, promovendo a distribuição de alimentos à população de baixa renda que tenha dificuldade de acesso à aquisição de alimentos (MENEZES, 2017).

Conforme Silva e Ferreira (2016), o Programa proporcionou como reflexo imediato oportunidades de fortalecimento da agricultura familiar, uma vez que os produtos agrícolas a serem doados às entidades consumidoras devem vir diretamente dos cultivos de agricultores familiares, respeitando as culturas típicas de cada região. Desta forma, as ações do PAA estão direcionadas para garantir, sobretudo, a segurança alimentar e nutricional, por meio da doação dos produtos da agricultura familiar às entidades públicas locais de assistência social.

Dentre as 6 (seis) modalidades de PAA existentes, segundo Camargo e Navas (2017), a modalidade "Compra com Doação Simultânea" tem incitado mudanças importantes na matriz produtiva das unidades familiares, notadamente no que concerne à diversificação produtiva, restaurando a policultura, que era comum na agricultura familiar e com a modernização acabou conduzindo os agricultores à especialização produtiva, monoculturas e produção de commodities, expondo estes à 
vulnerabilidade social. Camargo et al. (2016) corrobora com essa afirmação, por que para esses autores, o PAA na modalidade de "Compra com Doação Simultânea", possibilitou tanto o incremento da renda das famílias como o reconhecimento desses produtores rurais como agentes produtivos que contribuem com a segurança alimentar e nutricional de outros grupos sociais menos favorecidos.

Para Silva et al. (2015a), o PAA pode ser considerado um programa abrangente, porque potencializa e dinamiza toda a cadeia produtiva, desde a produção até o consumo. O programa estimula a agricultura familiar dando subsídios para que o pequeno produtor cultive e colha sua produção, promove a acesso de pessoas em situação de vulnerabilidade social a uma alimentação adequada, fomentando assim a agricultura familiar e objetivando o desenvolvimento da economia local. A experiência positiva do PAA transcendeu os limites do programa, incentivando uma mudança significativa para a inserção da agricultura familiar no Programa Nacional de Alimentação Escolar (PNAE) (SODRÉ; SALAMONI, 2016). O que ocorreu em 2009, quando se estabelece a imposição legal de que pelo menos $30 \%$ dos recursos expedidos pelo governo federal, por meio do Fundo Nacional de Desenvolvimento da Educação (FNDE), para aquisição de alimentação escolar sejam despendidos pelos estados e municípios na aquisição de alimentos advindos da agricultura familiar.

\section{PROCEDIMENTOS METODOLÓGICOS}

A presente pesquisa constitui-se do emprego do método qualitativo utilizando o estudo de caso como estratégia de pesquisa científica, além de, pesquisas bibliográficas, documentais e da experiência dos autores no local do estudo. De acordo com Yin (2010), estudo de caso é um delineamento mais adequado para a investigação de um fenômeno contemporâneo dentro de seu contexto real e por ser realizado no próprio local em que ocorrem os processos, seus resultados costumam serem mais fiéis. Acrescenta-se, que é de extrema importância que o pesquisador esteja imerso na realidade onde o estudo está sendo realizado.

Segundo Gil (2009), o estudo de caso consegue descrever a situação do contexto em que está sendo feita uma determinada pesquisa ou investigação. E a riqueza das informações detalhadas auxilia o pesquisador num maior conhecimento e numa possível resolução de problemas relacionados ao assunto estudado. Portanto, o estudo de caso é uma estratégia empírica utilizada para compreender profundamente um fenômeno da vida real dentro do seu contexto, com base numa lógica específica do planejamento, técnicas de coleta e análise de dados. Esta estratégia de pesquisa qualitativa leva em consideração as perspectivas dos diversos atores e permite ao pesquisador capturar vários processos em curso nas vidas das pessoas (YIN, 2010).

Ao final da execução do PAA Municipal, contabilizou-se quanto do total de recursos financeiros disponibilizados pela Prefeitura foi realmente executado na operacionalização do Programa. Além disso, identificou-se de quais áreas rurais eram os agricultores participantes do PAA e, quais produtos agropecuários e quantidades (em $\mathrm{kg}$ ), foram fornecidos pelos produtores durante o período de realização do PAA. Os dados foram tabulados no Microsoft Excel.

\section{RESULTADO E DISCUSSÃO}

\subsection{A execução do PAA Municipal em Maracanaú-CE}

O município de Maracanaú (Figura 1) está localizado na Região Metropolitana de Fortaleza, há apenas $20 \mathrm{~km}$ do centro da capital, tem uma área territorial de 106,648 $\mathrm{km}^{2}$ (MARACANAÚ, 2018), e 
possui uma população estimada de 224.804 habitantes, tornando-se o quarto município mais populoso do Estado do Ceará, sendo que, essa população é majoritariamente urbana (IBGE, 2018).

Figura 1 - Mapa ilustrativo do Estado do Ceará, destacando o município de Maracanaú-CE.

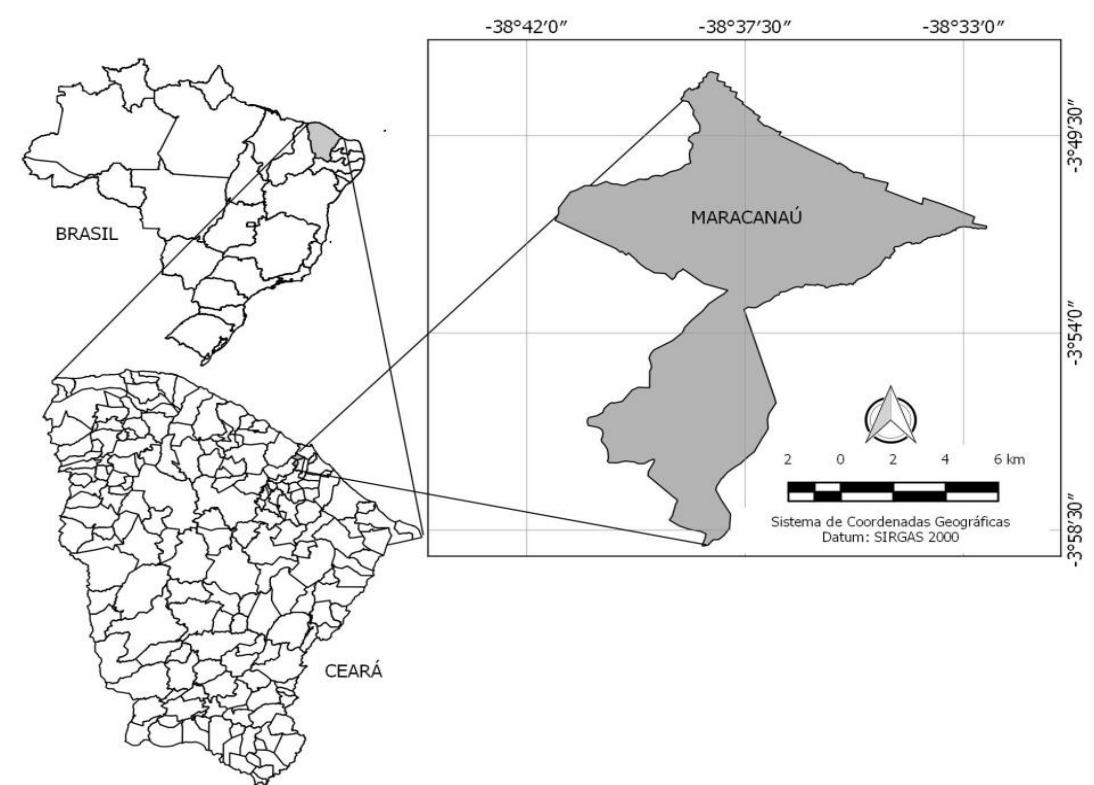

Fonte: Elaborado pelos Autores.

Em Maracanaú, a Lei Municipal $\mathrm{N}^{\circ} 1.188$, de 17 de abril de 2007, estabelece os limites da zona rural no Município, sendo inserida nessa condição, a Reserva Indígena dos Pitaguarys, a Comunidade do Mucunã e a Colônia Antônio Justa, as quais, durante anos, a agricultura familiar dessas áreas, não recebia o apoio financeiro necessário para o fortalecimento da atividade agrícola no município. Contudo, essa situação começou a se modificar a partir de 2007 quando foi firmado o primeiro convênio com o Ministério do Desenvolvimento Social e Combate à Fome (MDS) e o município de Maracanaú, através da Secretaria de Assistência Social e Cidadania (SASC) para a execução do PAA na modalidade Compra com Doação Simultânea.

Entretanto visando o fortalecimento da agricultura familiar no município, garantindo a compra de seus produtos agrícolas de maneira contínua, independente da paralisação do PAA Federal, a Prefeitura de Maracanaú, instituiu a Lei Municipal No 2.052, de 13 de agosto de 2013. A Lei estabelece que o limite individual de venda por agricultor/ano civil será, no máximo, de $50 \%$ do valor estabelecido no Decreto Federal No 7.775, de 04 de julho de 2012, que normatiza o PAA Federal, e suas alterações. Então em 2016, após articulação entre a SASC e a Secretaria de Finanças (SEFIN) conforme previsão na Lei Orçamentária Anual de 2015, ficou definido o valor de até $\mathrm{R} \$ 80.000,00$ para a aquisição dos produtos de agricultores familiares residentes em Maracanaú, nos meses de agosto a dezembro de 2016.

Os preços de referência dos produtos adquiridos seguirão a tabela editada pela Companhia Nacional de Abastecimento (CONAB) - Superintendência do Ceará e publicada em 01 de fevereiro de 2016, conforme Resolução n 59, de 10 de julho de 2013 do Grupo Gestor de PAA (GGPAA). Os gêneros alimentícios fornecidos pelos agricultores serão doados à Rede Socioassistencial do Município e a entidades ou organizações de assistência social sem fins lucrativos, aprovados em Chamada Pública $\mathrm{n}^{\circ}$ 01/2014 que visava selecionar Unidades Recebedoras no âmbito do PAA. As entidades deveriam ter, necessariamente, a inscrição no Conselho Municipal de Assistência Social (CMAS), segundo a Resolução 69, de 18 de setembro de 2014, editada pelo GGPAA. 
A seleção dos agricultores familiares obedeceu a ordem de classificação do resultado da Chamada Pública 01/2013 publicada em 09 de setembro de 2013, com validade de cinco anos, a qual selecionou produtores aptos a participar do PAA - Compra Com Doação Simultânea e do PAA Municipal. Ficou definido que cada agricultor poderia fornecer até $\mathrm{R} \$ 1.000,00$, beneficiando, portanto, 80 agricultores familiares residentes no município. O PAA Municipal foi executado seguindo a logística de ir buscar com um caminhão, semanalmente, a produção dos agricultores nos territórios onde residiam, no caso, Reserva Indígena e Mucunã, ambos fazem parte da área rural do município, e entregá-la na Unidade de Recebimento e Distribuição da Agricultura Familiar (URDAF) para posteriormente ser doado às entidades beneficiárias.

A aquisição de alguns produtos pelo PAA Municipal implicava que os agricultores familiares teriam que seguir algumas normas já estabelecidas pela Coordenação Local do Programa e que seguem a recomendação do MDS para execução do PAA - Compra com Doação Simultânea, como por exemplo, na aquisição de carnes e de polpas de frutas. Os produtores que quisessem fornecer carne bovina, suína ou ovina, deveriam realizar o abate de seus animais em Matadouros/Frigoríficos com o Selo de Inspeção Estadual (SIE) e entregar a Coordenação do Programa, documento fornecido pelo Matadouro, através do médico veterinário, comprovando o abate nesse Estabelecimento e atestando a qualidade da carne para consumo. Em Maracanaú há dois Matadouros/Abatedouro com SIE e registrado para o abate de bovinos, suínos, caprinos e ovinos.

Em relação as polpas de frutas, o agricultor deve ter seu estabelecimento para produzir e envasilhar polpa de frutas, registrado no Ministério da Agricultura Pecuária e Abastecimento (MAPA) e apresentar tal documento quando solicitado pela Coordenação do PAA, sendo obrigatório, sob pena de não ser recebido sua produção de polpa de frutas. Dessa forma, o procedimento para a entrega de carnes ou polpa de frutas foi seguida rigorosamente como mencionado e a não adequação a essas normativas, implicava que não seria recebido essas produções pela Coordenação do PAA Municipal.

Deve ser ressaltado que os agricultores familiares de Maracanaú são beneficiados com ações de Assistência Técnica e Extensão Rural (ATER), por um Engenheiro Agrônomo e um Técnico em Agropecuária. Essas ações de ATER são realizadas pela Prefeitura durante todo o ano, com ou sem a operacionalização do PAA. Petarly, Coelho e Souza (2017) destacam a importância das ações de ATER no meio rural, uma vez que, como os agentes de ATER geralmente estão em contato direto com os agricultores familiares realizando visitas periódicas as propriedades, as comunidades rurais percebem no agente de ATER a presença de alguém que pode contribuir para a mudança social que o local almeja.

Na Reserva Indígena e na Comunidade do Mucunã, os cultivos são realizados sem uso de agrotóxicos, com adubação orgânica, através da adição de esterco bovino ou ovino curtido, húmus de minhoca ou composto orgânico, obtido através da compostagem de diversos materiais orgânicos. Também são pulverizados nas plantas quando necessário, defensivos naturais para combater o ataque de insetos, as receitas com esses defensivos são amplamente divulgadas e utilizam produtos de fácil acesso na região, o que facilita seu emprego pelos agricultores. Situação semelhante foi observado por Padovan, Gomes e Padovan (2017) em estudo realizado no Mato Grosso do Sul, onde os agricultores familiares salientaram que é possível viabilizar a produção orgânica com menor custo em decorrência da utilização de insumos provenientes da unidade de produção (principalmente materiais orgânicos), da preparação de receitas caseiras à base de plantas para controlar pragas e doenças nas lavouras e da produção de sementes na propriedade, o que reduz a necessidade de aquisição de insumos externos.

Entretanto, os agricultores familiares no Estado do Ceará vêm enfrentando nos últimos 5 anos dificuldade para obter água e realizar a irrigação das áreas de cultivo, pois as chuvas ocorreram abaixo da média histórica. Uma vez que, no Estado, o período chuvoso se concentra em poucos meses no 
início do ano, de fevereiro a maio, sem água para irrigar, tornaria o plantio inviável no restante do ano.

Todavia, apesar dessa dificuldade na obtenção de água, o cultivo de hortaliças e fruteiras em Maracanaú é diversificado. De uma forma geral, são cultivadas plantas que se adaptam à região de altas temperaturas, como por exemplo, espécies de fruteiras (mangueira, cajueiro, etc.), hortaliças-frutos (abóbora, tomate, pimentão, etc.), hortaliças herbáceas (alface, couve-folha, etc.) e hortaliças tuberosas (batata-doce, macaxeira). O PAA geralmente estimula a diversificação da produção, além disso, os agricultores têm a oportunidade de inserir produtos disponíveis no próprio estabelecimento sem grandes investimentos. Esse fato, evidencia satisfação e avaliações positivas pelos agricultores familiares, quando consultados, tanto no que se refere à obtenção de uma renda alternativa quanto para a segurança alimentar, mesmo com a existência de problemas de operacionalização e de manutenção do programa (TSUKAMOTO; ASARI, 2017).

Na tabela 1, observa-se o quantitativo de agricultores participantes do Programa por área rural do município e o total de recursos financeiros empregados no PAA. Os agricultores familiares da Reserva Indígena são da Etnia Pitaguary e residem em três aldeias, Horto, Olho d'água e Santo Antônio, sendo considerada a área rural do município com maior produção agropecuária. Apesar disso, o território da Reserva Indígena possui um elevado índice de vulnerabilidade social, baseado no Cadastro Único Federal para programas sociais (MARACANAÚ, 2017).

Tabela 1 - Quantitativo de agricultores familiares e recursos financeiros utilizados por área rural no Município de Maracanaú-CE.

\begin{tabular}{ccc}
\hline Área Rural & Quantidade de Agricultores Familiares & $\begin{array}{c}\text { Recursos Financeiros } \\
\text { (R\$) }\end{array}$ \\
\hline Reserva Indígena & 52 & $46.738,15$ \\
Mucunã & 15 & $14.391,38$ \\
\hline Total & 67 & $61.129,53$ \\
\hline
\end{tabular}

Fonte: Dados da Pesquisa.

Baseado nos dados da tabela 1, verificou-se que 77,61\% dos agricultores participantes eram da Reserva Indígena devendo ser salientado que os indígenas são considerados público prioritário na execução do Programa, em qualquer uma das modalidades, quando executados via recursos financeiros do MDS ou da CONAB (MDS, 2018). Embora o PAA Municipal tenha sido efetivado com verbas municipais, ao conseguir incluir no Programa esse percentual de indígenas, verifica-se o compromisso da Prefeitura com um público que historicamente tem limitações na comercialização dos seus produtos agropecuários.

Apesar de ter sido assegurado para a execução do Programa verba de 80 mil reais, o total adquirido de gêneros alimentícios foi de 61 mil reais (Tabela 1), esse valor é menor que o autorizado para a realização do Programa. Devido à publicação no Diário Oficial da União da Portaria 37 de 8 de setembro de 2016 e sendo necessário iniciar o preenchimento de informações na Proposta de Participação do município no PAA - Compra com Doação Simultânea, o PAA Municipal teve antecipado sua finalização para o final de outubro de 2016. Todavia, deve ser ratificado que a efetivação do PAA Municipal foi uma enorme conquista dos agricultores familiares de Maracanaú pois foi possível amenizar a dificuldade de comercialização da produção, durante os meses que o PAA - Compra com Doação Simultânea não está sendo executado. 
Na figura 2 são apresentados os cinco produtos agropecuários mais fornecidos pelos agricultores familiares durante a operacionalização do Programa. Foram fornecidos pelos produtores no PAA Municipal, 27 produtos diversos entre hortaliças, frutas, carnes bovina e suína e produtos processados como bolos, doces e polpa de frutas. A manga foi o produto mais entregue pelos agricultores pois o período de ocorrência do PAA coincidiu com a safra da fruta que se inicia em setembro indo até março, sendo a Reserva Indígena, a área com maior produção da fruta em Maracanaú, acrescenta-se, que é uma cultura bem-adaptada às condições locais de clima e solo. A bananeira é considerada uma planta bastante adaptada às condições climáticas do Estado do Ceará, sendo observada uma importante área produtiva, nos municípios da região metropolitana de Fortaleza.

Figura 2. Produtos agropecuários fornecidos pelos agricultores familiares durante a execução do PAA Municipal em Maracanaú-CE.

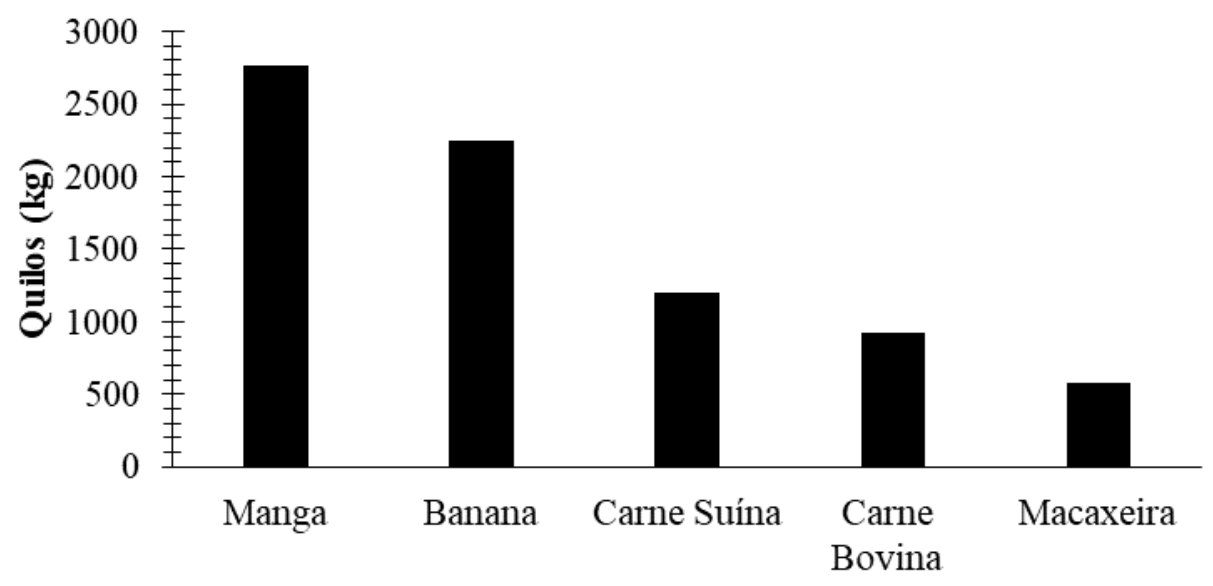

Fonte: Dados da Pesquisa.

Os produtos entregues pelos agricultores foram doados à Rede Socioassistencial e à Rede de SAN do município, a citar: 11 Centros de Referências da Assistência Social (CRAS), 01 Centro de Referência Especializado em Assistência Social (CREAS), 01 Centro POP, 01 Centro de Convivência do Idoso (CCI), 01 Restaurante Popular, 06 Cozinhas Comunitárias e 01 Banco de Alimentos beneficiando grande número de pessoas em situação de vulnerabilidade e insegurança alimentar e nutricional, por meio da melhoria da qualidade e diversidade da alimentação oferecida nestes equipamentos públicos.

Nos últimos anos tem crescido o estímulo à produção da agricultura familiar para abastecer equipamentos públicos, como restaurantes populares e cozinhas comunitárias, ou escolas, através do PAA e do PNAE, respectivamente. Dessa forma as políticas públicas exercem um papel importante ao viabilizar investimentos e garantir mercados através das compras públicas de alimentos para serem repassados à população por meio dos programas de proteção e promoção social, ao mesmo tempo em que contribuem para viabilizar a agricultura familiar a partir de diferentes fontes de renda (CONTI; BAZOTTI; RADOMSKY, 2015).

\section{CONSIDERAÇÕES FINAIS}

A concretização do PAA Municipal fortalece a agricultura familiar local propiciando renda aos agricultores, acrescenta-se que as atividades de ATER desenvolvidas no município com os produtores que participam do Programa resultaram na implantação do manejo agroecológico, principalmente para aqueles 
que cultivam hortaliças e frutas em suas áreas. Logo, foi possível constatar que a partir da adoção dos princípios agroecológicos pelos agricultores, observou-se cultivo diversificado de espécies vegetais, sem uso de agrotóxicos, com adubação orgânica, dentre outras orientações, como o uso de defensivos naturais para combater insetos pragas e a realização de rotação de cultura. Essas ações articuladas resultaram em alimentos (hortaliças e frutas) saudáveis e seguros, sem contaminação por resíduos de produtos químicos.

O PAA Municipal apresentou significativa importância por garantir a continuidade do processo de aquisição de produtos da agricultura familiar, atuando na melhoria da capacidade de acesso a comercialização de produtos agropecuários pelos agricultores familiares de Maracanaú-CE. Além disso, a continuidade do programa permite a regularidade no acesso à alimentação adequada e saudável às pessoas atendidas na rede socioassistencial contribuindo para a consecução da Política de Segurança Alimentar e Nutricional no município.

\section{REFERÊNCIAS}

AZEVEDO, F. F.; PESSÔA, V. L. S. O Programa Nacional de Fortalecimento da Agricultura Familiar no Brasil: uma análise sobre a distribuição regional e setorial dos recursos. Sociedade \& Natureza, v. 23, n. 3, p. 483-496, 2011.

BACCARIN, J. G. et al. Indicadores de Avaliação das Compras da Agricultura Familiar para Alimentação Escolar no Paraná, Santa Catarina e São Paulo. Revista de Economia e Sociologia Rural, v. 55, n. 01, p. 103-122, 2017.

BEZERRA, G. J.; SCHLINDWEIN, M. M. Agricultura familiar como geração de renda e desenvolvimento local: uma análise para Dourados, MS, Brasil. INTERAÇÕES, v. 18, n. 1, p. 3-15, 2017.

BIANCARDI, C. C. S. et al. Viabilidade econômica da produção familiar de alimentos para os mercados institucionais de Alegre-ES. Extensão Rural, v.23, n.2, p. 85-101, 2017.

CAMARGO, J. S. M.; NAVAS, R. Programas institucionais de compra da agricultura familiar no município de Ribeirão Grande/SP: uma análise a partir da produção e consumo. Revista Nera, v. 20, n. 35 p. 230-245, 2017.

CAMARGO, R. A. L. et al. O PAA e PNAE em assentamentos PDS no Norte Paulista. Retratos de Assentamentos, v. 19, n. 1, p. 149-173, 2016.

CONTI, I. L.; BAZOTTI, A.; RADOMSKY, G. F. W. Agricultura familiar e segurança alimentar e nutricional: um estudo sobre a relação produção-consumo nos municípios de Toledo (PR) e Contagem (MG). Revista Extensão Rural, v. 22, n. 1, p. 56-86, 2015.

GAZOLLA, M.; SCHNEIDER, S. Qual "Fortalecimento" da Agricultura Familiar? Uma análise do Pronaf crédito de custeio e investimento no Rio Grande do Sul. Revista de Economia e Sociologia Rural, v. 51, n. 1, p. 045-068, 2013.

GIL, A. C. Como elaborar projetos de pesquisa. 4. ed. São Paulo: Atlas, 2009. 175p.

GRISA, C.; SCHNEIDER, S. Três Gerações de Políticas Públicas para a Agricultura Familiar e Formas de Interação entre Sociedade e Estado no Brasil. Revista de Economia e Sociologia Rural, v. 52, Supl. 1, p. S125-S146, 2014.

GRISA, C.; WESZ JUNIOR, V. J.; BUCHWEITZ, V. D. Revisitando o Pronaf: velhos questionamentos, novas interpretações. Revista de Economia e Sociologia Rural, v. 52, n. 02, p. 323-346, 2014. 
HANASHIRO, M. M. et al. Transferência de tecnologias apropriadas para a agricultura familiar: uma experiência de ação integrada no Estado de São Paulo. Cadernos de Ciência \& Tecnologia, v. 28, n. 1, p. $51-80,2011$.

IBGE. Instituto Brasileiro de Geografia e Estatística. 2018. Disponível em: 〈http://www.ibge.gov.br〉. Acesso em: 15 de agosto de 2018.

LUNAS, D. A. L.; CARDOSO JÚNIOR, H. M.; LIMA, C. V. S. Agricultura Familiar e Desenvolvimento Territorial Rural: experiências e desafios da política pública no Sudoeste Goiano. Redes (St. Cruz Sul, Online), v. 22, n. 3, p. 113-144, 2017.

MACEDO, A de C. et al. Os limites de políticas públicas voltadas para agricultura familiar em promover organização social: o caso do assentamento 23 de maio. Extensão Rural, v. 24, n. 2, p. 102-113, 2017.

MARACANAÚ. Prefeitura Municipal de Maracanaú. 2018. Disponível em:

<http://www.maracanau.ce.gov.br>. Acesso em: 6 de agosto de 2018.

Relatório de Gestão 2016. Secretaria de Assistência Social e Cidadania. Prefeitura

Municipal de Maracanaú, 2017.

MARQUES, P. E. M.; MOAL, M. F. L.; ANDRADE, A. G. F. Programa de Aquisição de Alimentos (PAA) no Estado de São Paulo. Ruris, v. 8, n. 1, p. 63-89, 2014.

MDS. Ministério do Desenvolvimento Social. 2018. Disponível em: 〈http://www.mds.gov.br〉. Acesso em: 06 de julho de 2018.

MENEZES, G. V. O Programa de Aquisição de Alimentos - modalidade leite (PAA-Leite) na regional de Arapiraca no agreste alagoano: limites e potencialidades. Diversitas Journal, v. 1, n. 1, p. 21-25, 2016.

NASCIMENTO, J. S. et al. Produção agropecuária, agregação de valor e comercialização pela agricultura familiar no Estado do Mato Grosso do Sul. Redes (St. Cruz Sul, Online), v. 21, n. 3, p. 320 - 334, 2016.

PADOVAN, M. P.; GOMES, J. B. P.; PADOVAN, D. S. da S. Produção orgânica no âmbito da agricultura familiar em Mato Grosso do Sul. Redes (St. Cruz Sul, Online), v. 22, n. 3, p. 316-342, 2017.

PAULA, M. M. de; KAMIMURA, Q. P.; SILVA, J. L. G. Mercados institucionais na agricultura familiar dificuldades e desafios. Revista de Política Agrícola, v. 23, n. 1, p. 33-43, 2014.

PETARLY, R. R.; COELHO, P. S.; SOUZA, W. P. de. Assistência técnica e extensão rural cooperativa: o perfil e o trabalho dos agentes de campo em uma cooperativa agropecuária em Minas Gerais, Brasil.

Mundo Agrario, v. 18, n. 38, e059, 2017.

RIGON, S do A.; BEZERRA, I. Segurança alimentar e nutricional, agricultura familiar e compras institucionais: desafios e potencialidades. Demetra, v. 9, n. 2, p. 435-443, 2014.

SALGADO, R. J. dos S. F.; DIAS, M. M. Análise da influência do Programa de Aquisição de Alimentos (PAA) sobre a qualidade de vida de agricultores familiares do município de Viçosa/MG. Perspectivas em Políticas Públicas, v. 1, n. 11, p. 65-91, 2013.

SANTANA, A. C. et al. Mercado institucional e agricultura urbana e periurbana em Curuçambá, Ananindeua, Pará: oportunidades e desafios. Revista Brasileira de Gestão e Desenvolvimento Regional, v. 13, n. 1, p. 316-338, 2017.

SCHEUER, J. M. et al. Aspectos socioeconômicos dos agricultores familiares da associação dos pequenos produtores da região do Alto Sant'ana, Mato Grosso. Revista Brasileira de Gestão e Desenvolvimento Regional, v. 12, n. 1, p. 85-106, 2016. 
SCHNEIDER, S.; CASSOL, A. Diversidade e heterogeneidade da agricultura familiar no Brasil e algumas implicações para políticas públicas. Cadernos de Ciência \& Tecnologia, v. 31, n. 2, p. 227-263, 2014.

SECCHI, L. Análise de políticas públicas: Diagnóstico de problemas, recomendação de soluções. $1^{\circ}$ ed. São Paulo: Cengage Learning, 2016. 252p.

SILVA, E. S. et al. O estado da arte das políticas públicas para o campo: uma abordagem do Programa de Aquisição de Alimentos no Estado do Pará. Reflexões Econômicas, v. 1, n. 1, p. 153-178, 2015 a.

SILVA, R. P. et al. Pronaf e a produção familiar: a diversidade do tecido social na órbita do estado. Retratos de Assentamentos, v. 18, n. 2, p. 341-366, 2015 b.

SILVA, T. C.; FERREIRA, P. R. O Programa de Aquisição de Alimentos sob a Ótica dos Atores Sociais Envolvidos. Desenvolvimento em Questão, v. 14, n. 33, p. 301-329, 2016.

SODRÉ, M. T.; SALAMONI, G. A coexistência do pensamento cartesiano e sistêmico: as limitações territoriais enfrentadas pelo PAA e PNAE em Pelotas/RS. Sociedade \& Natureza, v. 28, n.3, p. 457-471, 2016.

SOUZA-ESQUERDO, V. F.; BERGAMASCO, S. M. P. P. Políticas públicas para a agricultura familiar brasileira: um estudo sobre o Pronaf nos municípios do circuito das frutas-SP. Revista Extensão Rural, v. 22, n. 1, p. 9-35, 2015.

TRICHES, R. M.; GRISA, K. Entre mudanças e conservadorismos: uma análise dos programas de aquisição de alimentos (PAA e PNAE) a partir da retórica da intransigência. Revista NERA, v. 18, n. 26, p. 10-27, 2015.

TSUKAMOTO, R. Y.; ASARI, A. Y. Campo e o Estado: a atuação dos seus atores na manutenção das unidades de produção familiar. Revista GeoNordeste, v. 28, n. 1, p. 82-97, 2017.

YIN. R. K. Estudo de caso: planejamento e métodos. $4^{\circ}$ ed. Porto Alegre: Bookman, 2010. 248 p. 